\title{
Decolorization of Reactive Red 239 Via Heat Activated Persulfate
}

\author{
Ozlem Esen Kartal \\ Department of Chemical Engineering, İnönü University, Malatya, Turkey
}

\section{Email address:}

ozlem.kartal@inonu.edu.tr

\section{To cite this article:}

Ozlem Esen Kartal. Decolorization of Reactive Red 239 via Heat Activated Persulfate. American Journal of Physical Chemistry. Vol. 7, No. 3, 2018, pp. 45-49. doi: 10.11648/j.ajpc.20180703.11

Received: August 14, 2018; Accepted: September 3, 2018; Published: October 9, 2018

\begin{abstract}
Effluents of cotton dyeing process of textile industry is considered as extremely polluted due to presence of unfixed azo dyes and auxiliary chemicals. The complex aromatic structure and non-biodegradability nature of azo dyes involved new and efficient treatment technologies to eliminate intense color from textile wastewater. In recent years, in-situ chemical oxidation technology (ISCO) using persulfate $\left(\mathrm{S}_{2} \mathrm{O}_{8}{ }^{2-}\right)$ as an oxidant has appeared to be a promising method for removal of azo dyes. $\mathrm{S}_{2} \mathrm{O}_{8}{ }^{2-}$ can be activated by UV, heat or transition metals to generate sulfate radical $\left(\mathrm{SO}_{4}{ }^{-}\right)$. In this study, decolorization of Reactive Red 239 (RR239) azo dye via heat activated $\mathrm{S}_{2} \mathrm{O}_{8}{ }^{2-}$ was explored. Experiments were conducted in a cylindrical batch reactor equipped with a water jacket. Effect of parameters such as temperature, $\mathrm{pH}$ and $\mathrm{S}_{2} \mathrm{O}_{8}{ }^{2-}$ concentration on decolorization of $\mathrm{RR} 239$ was investigated. The results show that decolorization efficiency was enhanced with increasing temperature from 45 to $55^{\circ} \mathrm{C}$ but further increase in temperature did not enhance decolorization. The pseudo first order rate constant values fit well Arrhenius equation, yielding an activation energy of $108.75 \mathrm{~kJ} \mathrm{~mol}^{-1}$ for decolorization of RR239. The highest decolorization efficiency was obtained at $\mathrm{pH}=3$ under the tested $\mathrm{pH}$ range. $\mathrm{As}_{2} \mathrm{O}_{8}{ }^{2-}$ concentration increased decolorization efficiency increased. 89.67\% and $39.05 \%$ decolorization and aromatic degradation efficiencies were observed within 120 minutes of reaction time, respectively. These results show that heat activated $\mathrm{S}_{2} \mathrm{O}_{8}{ }^{2-}$ method was a feasible method for decolorization of RR239.
\end{abstract}

Keywords: Heat Activated Persulfate, Sulfate Radical, Azo Dye, Decolorization

\section{Introduction}

Remediation of a large volume of wastewater originating from textile industry is of basic importance for preventing water pollution. Effluents of cotton dyeing process of textile industry are characterized by having an intense color and a low $\mathrm{BOD}_{5} / \mathrm{COD}$ ratio due to presence of unfixed reactive dyes. $\mathrm{BOD}_{5} / \mathrm{COD}$ ratio ranges from 0.06 to 0.35 , indicating a low biodegradability of textile effluents [1-2]. Since reactive dyes have a low dye-fiber fixation rate in comparison with other dyes, a considerable amount of them is lost in dyeing process. The release of them into receiving water bodies causes non-aesthetic pollution, eutrophication and reduction of light penetration [3-5]. The chromophore group of reactive dyes is mostly azo type and azo dyes are known to be toxic and mostly nonbiodegradable. Although several treatment technologies have been considered for textile wastewater so far, they are not efficient in the presence of nonbiodegradable azo dyes. Removal of azo dyes by conventional aerobic biological treatment is not amenable and aromatic amines which show more toxic effect than dye molecules are formed under anaerobic conditions. Physical methods transfer dyes from one phase to another and cause secondary pollution [6]. Therefore, an efficient treatment technology for removal of azo dyes from textile effluents should be developed to meet stringent discharge limits. Recently, in-situ chemical oxidation technology (ISCO) in which hydrogen peroxide $\left(\mathrm{H}_{2} \mathrm{O}_{2}\right)$, persulfate $\left(\mathrm{S}_{2} \mathrm{O}_{8}{ }^{2-}\right)$, permanganate $\left(\mathrm{MnO}_{4}^{-}\right)$and ozone $\left(\mathrm{O}_{3}\right)$ are used as an oxidant has emerged as an alternative to conventional technologies[7]. $\mathrm{S}_{2} \mathrm{O}_{8}{ }^{2-}$ is a strong oxidant with an oxidation-reduction potential of $2.01 \mathrm{~V}$ and offers some advantages such as high stability, high aqueous solubility, high oxidation-reduction potential and relatively low cost over other oxidants [8-9]. When $\mathrm{S}_{2} \mathrm{O}_{8}{ }^{2-}$ is activated, sulfate radical $\left(\mathrm{SO}_{4}{ }^{-}\right)$with an oxidation-reduction potential of +2.5 to $+3.1 \mathrm{~V}$ vs. NHE is generated. $\mathrm{SO}_{4}^{-{ }^{-}}$is capable of degradation of hazardous water contaminants through electron transfer [10]. $\mathrm{S}_{2} \mathrm{O}_{8}{ }^{2-}$ can be activated by UV [6, 11-14], heat [10, 15-17] and 
transition metals $[9,18]$. The related equations with these activation methods are given as follows [19-20]:

$$
\begin{gathered}
\mathrm{S}_{2} \mathrm{O}_{8}^{2-}+\text { heat } \rightarrow 2 \mathrm{SO}_{4}^{--} \\
\mathrm{S}_{2} \mathrm{O}_{8}^{2-}+\mathrm{h} v \rightarrow 2 \mathrm{SO}_{4}^{--} \\
\mathrm{S}_{2} \mathrm{O}_{8}^{2-}+\mathrm{Fe}^{2+} \rightarrow \mathrm{SO}_{4}^{--}+\mathrm{SO}_{4}^{2-}+\mathrm{Fe}^{3+}
\end{gathered}
$$

Once $\mathrm{SO}_{4}{ }^{-}$is generated in-situ by these methods, organic compounds $(\mathrm{R})$ are degradated through chain reactions as summarized in the following equations[6]:

$$
\begin{gathered}
\mathrm{SO}_{4}^{{ }^{-}}+\mathrm{RH}_{2} \rightarrow \mathrm{SO}_{4}^{2-}+\mathrm{H}^{+}+\mathrm{RH} \\
\mathrm{RH}+\mathrm{S}_{2} \mathrm{O}_{8}^{2-} \rightarrow \mathrm{R}+\mathrm{SO}_{4}{ }^{2-}+\mathrm{H}^{+}+\mathrm{SO}_{4}^{{ }^{-}} \\
\mathrm{SO}_{4}^{-^{-}+} \mathrm{RH} \rightarrow \mathrm{SO}_{4}^{2-}+\mathrm{H}^{+}+\mathrm{R} \\
2 \mathrm{R} \cdot \mathrm{RR}
\end{gathered}
$$

The objective of this study was to investigate decolorization of a model azo dye, Reactive Red 239 (RR239), via heat activated $\mathrm{S}_{2} \mathrm{O}_{8}{ }^{2-}$. The effect of process variables on decolorization of RR239 was evaluated.

\section{Method}

\subsection{Materials}

All chemicals used in this study were of analytical grade and used without further purification. $\mathrm{Na}_{2} \mathrm{~S}_{2} \mathrm{O}_{8}(\geq 99.9 \%)$ was acquired from Merck. A commercially available RR239 was from DyStar. $\mathrm{HCl}(37 \% \mathrm{w} / \mathrm{w})$ was purchased from Merck and $\mathrm{NaOH}$ was purchased from Sigma-Aldrich.

\subsection{Experimental Procedure}

Decolorization of RR239 was performed in a cylindrical batch reactor using RR239 solution of appropriate concentration prepared by diluting $100 \mathrm{mg} \mathrm{dm}^{-3}$ stock solution. For each run, $0.5 \mathrm{dm}^{3}$ RR239 solution at desired concentration was put into reactor and stirred by a magnetic stirrer (IKA RH KT/C) for 10 minutes. The initial $\mathrm{pH}$ of RR239 solution was adjusted using either dilute $\mathrm{NaOH}$ or $\mathrm{HCI}$ solution. After addition of $\mathrm{Na}_{2} \mathrm{~S}_{2} \mathrm{O}_{8}$, the reaction was initiated. The temperature of reaction medium was hold at predetermined temperature by circulating water heated in the thermostatic water bath (Nüve BS 302) through the water jacket of the reactor.

\subsection{Analysis}

Samples taken from reaction medium at regular time intervals were analyzed by means of a double beam Shimadzu UV-1700 Pharmaspec UV-Visible Spectrophotometer. The concentration of RR239 was determined by measuring the absorbance at maximum wavelength of $540 \mathrm{~nm}$. Decolorization efficiency of the samples was calculated as follows:

$$
\text { Decolorization \% }=\left[\mathrm{C}_{\mathrm{o}}\left({ }_{540 \mathrm{~nm})}-\mathrm{C}_{540 \mathrm{~nm})} / \mathrm{C}_{\mathrm{o}}(540 \mathrm{~nm})\right] \times 100(8)\right.
$$

Aromatic degradation efficiency of the samples was calculated as follows:

$$
\text { Degradation } \%=\left[\mathrm{C}_{\mathrm{o}}(289 \mathrm{~nm})-\mathrm{C}(289 \mathrm{~nm}) / \mathrm{C}_{\mathrm{o}}(289 \mathrm{~nm})\right] \times 100(9)
$$

where $\mathrm{C}_{\mathrm{o}}$ and $\mathrm{C}$ are the initial and treated dye concentrations at corresponding wavelengths, respectively.

\section{Results and Discussion}

\subsection{Effect of Temperature}

The effect of temperature was investigated in the temperature range of $45-60{ }^{\circ} \mathrm{C}$ using $2 \mathrm{mM} \mathrm{Na}_{2} \mathrm{~S}_{2} \mathrm{O}_{8}$ at initial RR239 concentration of $40 \mathrm{mg} \mathrm{dm}$. As is evident from Figure 1, decolorization efficiency increased with increasing temperature up to $55^{\circ} \mathrm{C}$ and no enhancement was observed with a further increase in temperature within 120 minutes of reaction time.

Linear plot of $\ln (\mathrm{Co} / \mathrm{C})$ vs. time exhibits pseudo first order kinetic model for decolorization of RR239 via heat activated $\mathrm{Na}_{2} \mathrm{~S}_{2} \mathrm{O}_{8}$. Pseudo first order kinetic model can be expressed as:

$$
\ln (\mathrm{Co} / \mathrm{C})=\mathrm{k}_{\mathrm{app}} \mathrm{t}
$$

where $\mathrm{C}_{\mathrm{o}}$ and $\mathrm{C}$ are initial and treated dye concentrations, $\mathrm{k}_{\mathrm{app}}$ is pseudo first order rate constant and $t$ is reaction time.

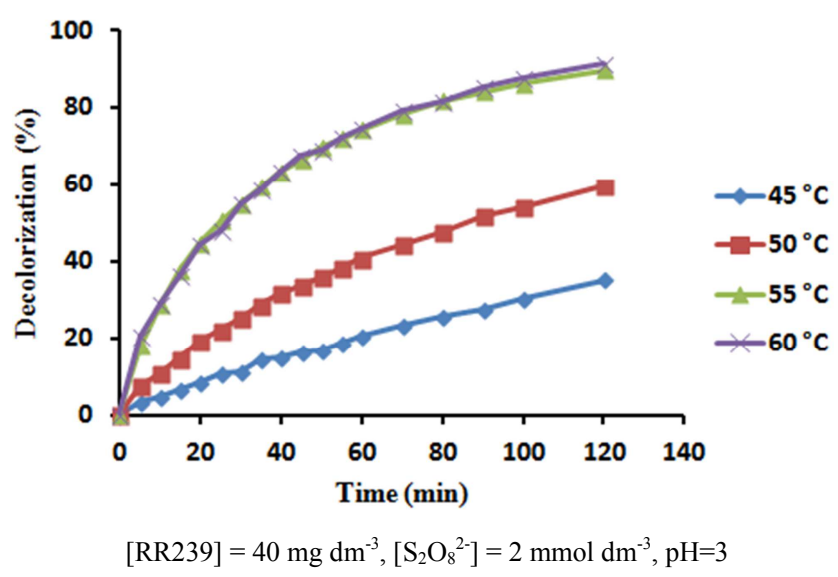

Figure 1. Effect of temperature on decolorization of RR239.

As shown in Figure 2, experimental data fit well to pseudo first order kinetic model evidenced by high correlation coefficients $\left(\mathrm{R}^{2}\right)$. The pseudo first order rate constant values were increased from 0.0035 to $0.0196 \mathrm{~min}^{-1}$ as temperature increased from $45^{\circ} \mathrm{C}$ to $60{ }^{\circ} \mathrm{C}$. Besides, Arrhenius equation (11) was used to determine the activation energy for decolorization of RR239.

$$
\ln \left(\mathrm{k}_{\mathrm{app}}\right)=\ln \mathrm{A}-\mathrm{E}_{\mathrm{a}} / \mathrm{RT}
$$

where $\mathrm{A}$ is the frequency factor, Ea is the activation energy, $\mathrm{R}$ is the gas constant and $\mathrm{T}$ is the absolute temperature. Arrhenius dependency of pseudo first order rate constants obtained for decolorization of RR239 over the range of temperature studied is given in Figure 3. The activation 
energy was calculated as $108.75 \mathrm{~kJ} \mathrm{~mol}^{-1}$ from this figure.

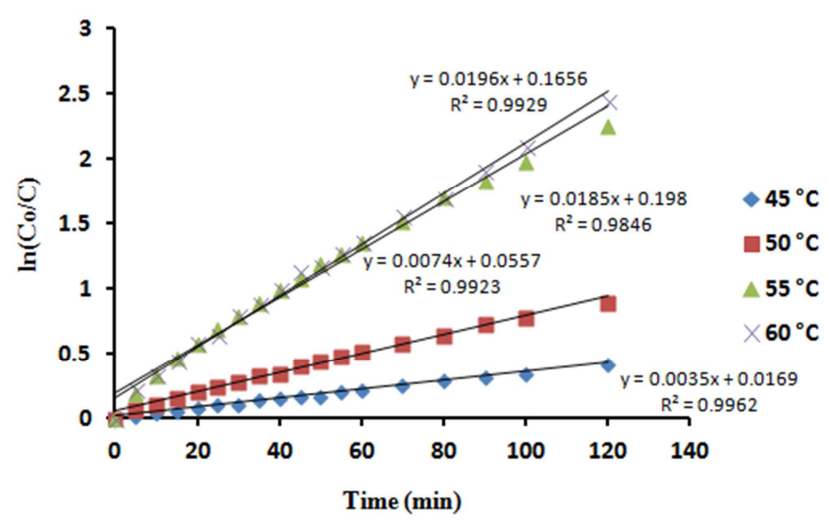

Figure 2. Kinetics of decolorization of RR239.

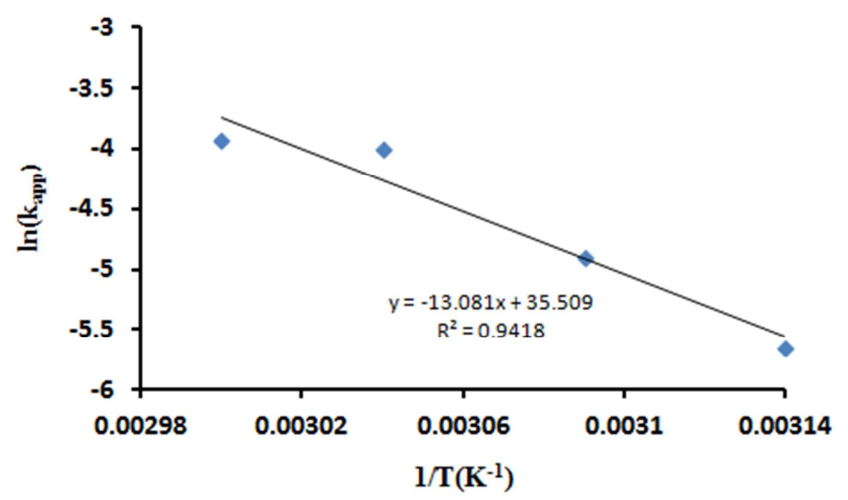

Figure 3. Arrhenius plot of pseudo first order rate constants.

\subsection{Effect of $p H$}

The effect of $\mathrm{pH}$ on decolorization of $\mathrm{RR} 239$ was investigated in the range of 3-9 at $55^{\circ} \mathrm{C}$ using $2 \mathrm{mM} \mathrm{Na}_{2} \mathrm{~S}_{2} \mathrm{O}_{8}$ with initial RR239 concentration of $40 \mathrm{mg} \mathrm{dm}^{-3}$. As can be deduced from Figure 4, an appreciable decolorization was observed at $\mathrm{pH}=3$ in compared to that in neutral and basic conditions. In acidic condition $\mathrm{S}_{2} \mathrm{O}_{8}{ }^{2-}$ can be decompose into $\mathrm{SO}_{4}{ }^{-}$through following equations [14]:

$$
\begin{gathered}
\mathrm{S}_{2} \mathrm{O}_{8}{ }^{2-}+\mathrm{H}^{+} \rightarrow \mathrm{HS}_{2} \mathrm{O}_{8}^{-} \\
\mathrm{HS}_{2} \mathrm{O}_{8}{ }^{-} \rightarrow \mathrm{SO}_{4}^{-{ }^{-}}+\mathrm{SO}_{4}{ }^{2-}+\mathrm{H}^{+}
\end{gathered}
$$

In neutral and basic conditions, $\mathrm{SO}_{4}{ }^{--}$is transformed to hydroxyl radical $(\mathrm{OH})$ by equations 14 and 15 [16].

$$
\begin{gathered}
\mathrm{SO}_{4}^{{ }^{-}}+\mathrm{H}_{2} \mathrm{O} \rightarrow \mathrm{SO}_{4}^{2-}+\mathrm{OH}^{-}+\mathrm{H}^{+} \\
\mathrm{SO}_{4}^{{ }^{-}}+\mathrm{OH}^{-} \rightarrow \mathrm{SO}_{4}^{2-}+\mathrm{OH}^{-}
\end{gathered}
$$

$\mathrm{OH}^{-}$is another strong radical with an oxidation-reduction potential of +1.8 to $+2.7 \mathrm{~V}$ vs. NHE. $\mathrm{SO}_{4}{ }^{-}$is preferable because of its higher oxidation-reduction potential, longer half life and ability of oxidizing organic compounds selectively [21-22]. The $\mathrm{pH}$ of solution considerably influences presence of predominant radical in the reaction medium. In this study, decolorization efficiency followed the order of $\mathrm{pH}=3>\mathrm{pH}=7>$ $\mathrm{pH}=$ 9. Similar result was reported by Jiang et al. [10] for oxidation of fluoroquinolone antibiotics via heat activated $\mathrm{S}_{2} \mathrm{O}_{8}{ }^{2-}$.

\subsection{Effect of $\mathrm{S}_{2} \mathrm{O}_{8}{ }^{2-}$ Concentration}

In order to investigate the effect of $\mathrm{S}_{2} \mathrm{O}_{8}{ }^{2-}$ concentration a series of experiments was conducted. $\left[\mathrm{S}_{2} \mathrm{O}_{8}{ }^{2-}\right]_{\mathrm{o}} /[\mathrm{RR} 239]_{\mathrm{o}}$ mole ratios was obtained by fixing [RR239] $]_{0}$ to $40 \mathrm{mg} \mathrm{dm}^{-3}$ $(0.03897 \mathrm{mM})$ and varying $\left[\mathrm{S}_{2} \mathrm{O}_{8}{ }^{2-}\right]_{\mathrm{o}}$ from $0.5 \mathrm{mM}$ to $4 \mathrm{mM}$. As shown in Figure 5, decolorization efficiency increased with increasing $\left[\mathrm{S}_{2} \mathrm{O}_{8}{ }^{2-}\right]_{\mathrm{o}} /[\mathrm{RR} 239]_{\mathrm{o}}$ ratio. As expected, increasing $\mathrm{S}_{2} \mathrm{O}_{8}{ }^{2-}$ concentration resulted in generation of more $\mathrm{SO}_{4}{ }^{-}$in the solution, thus leading to higher decolorization efficiency. Based on these results a higher $\mathrm{S}_{2} \mathrm{O}_{8}{ }^{2-}$ concentration would provide high decolorization efficiency. This result was in agreement with the studies reported by Tan et al. [15] and Ghauch et al. [16].

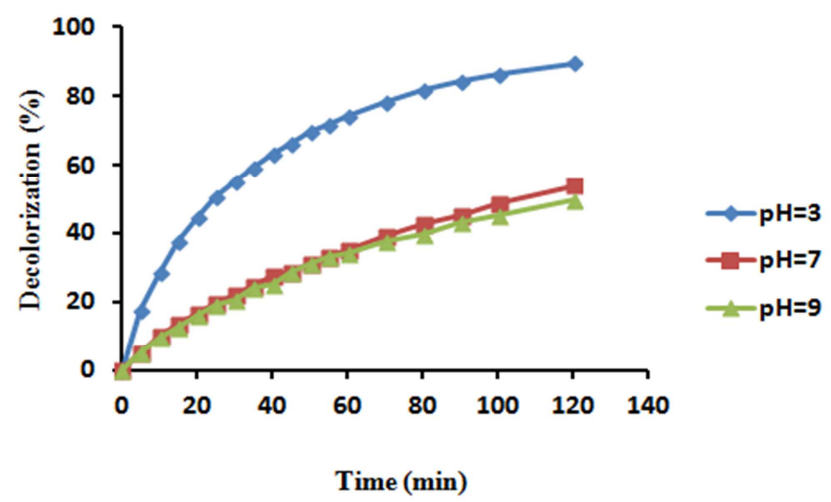

[RR239] $=40 \mathrm{mg} \mathrm{dm}^{-3},\left[\mathrm{~S}_{2} \mathrm{O}_{8}{ }^{2-}\right]=2 \mathrm{mmol} \mathrm{dm}^{-3}, \mathrm{~T}=55^{\circ} \mathrm{C}$

Figure 4. Effect of $p H$.

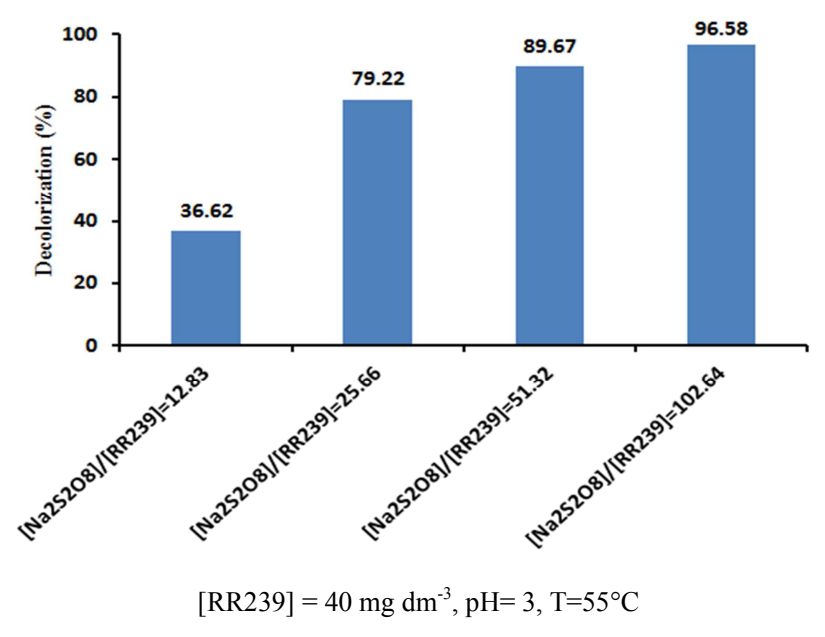

Figure 5. Effect of $\mathrm{S}_{2} \mathrm{O}_{8}{ }^{2}$ Concentration.

\subsection{UV-Visible Spectral Changes of RR239}

As is evident from Figure 6, two main peaks at 289 and $540 \mathrm{~nm}$ were appeared in UV-visible spectra of RR239 measured over the wavelength range of 190-800 nm during 120 minutes of reaction time. The absorbance peak at $540 \mathrm{~nm}$ in visible region is attributed to chromophoric group of RR239 and peak in the UV region at 289 is attributed to 
benzene ring. Accordingly, decolorization of RR239 via heat activated $\mathrm{S}_{2} \mathrm{O}_{8}{ }^{2-}$ was monitored by measuring the absorbance at $540 \mathrm{~nm}$, while aromatic degradation was followed by measuring the absorbance at $289 \mathrm{~nm}$. Decolorization and aromatic degradation efficiencies obtained using $2 \mathrm{mM}$ $\mathrm{Na}_{2} \mathrm{~S}_{2} \mathrm{O}_{8}$ with initial RR239 concentration of $40 \mathrm{mg} \mathrm{dm}^{-3}$ at $55^{\circ} \mathrm{C}$ and $\mathrm{pH}=3$ were given in Figure $7.89 .67 \%$ of decolorization and $39.05 \%$ of degradation efficiency levels were reached at the end of 120 minutes. Decolorization occurred via cleavage of $-\mathrm{N}=\mathrm{N}$ - bond and almost complete decolorization was achieved within 120 minutes of reaction time. However, decolorization does not mean the removal of RR239 completely. Colorless intermediates are expected to be formed during reaction. Therefore, aromatic degradation required longer time than decolorization.

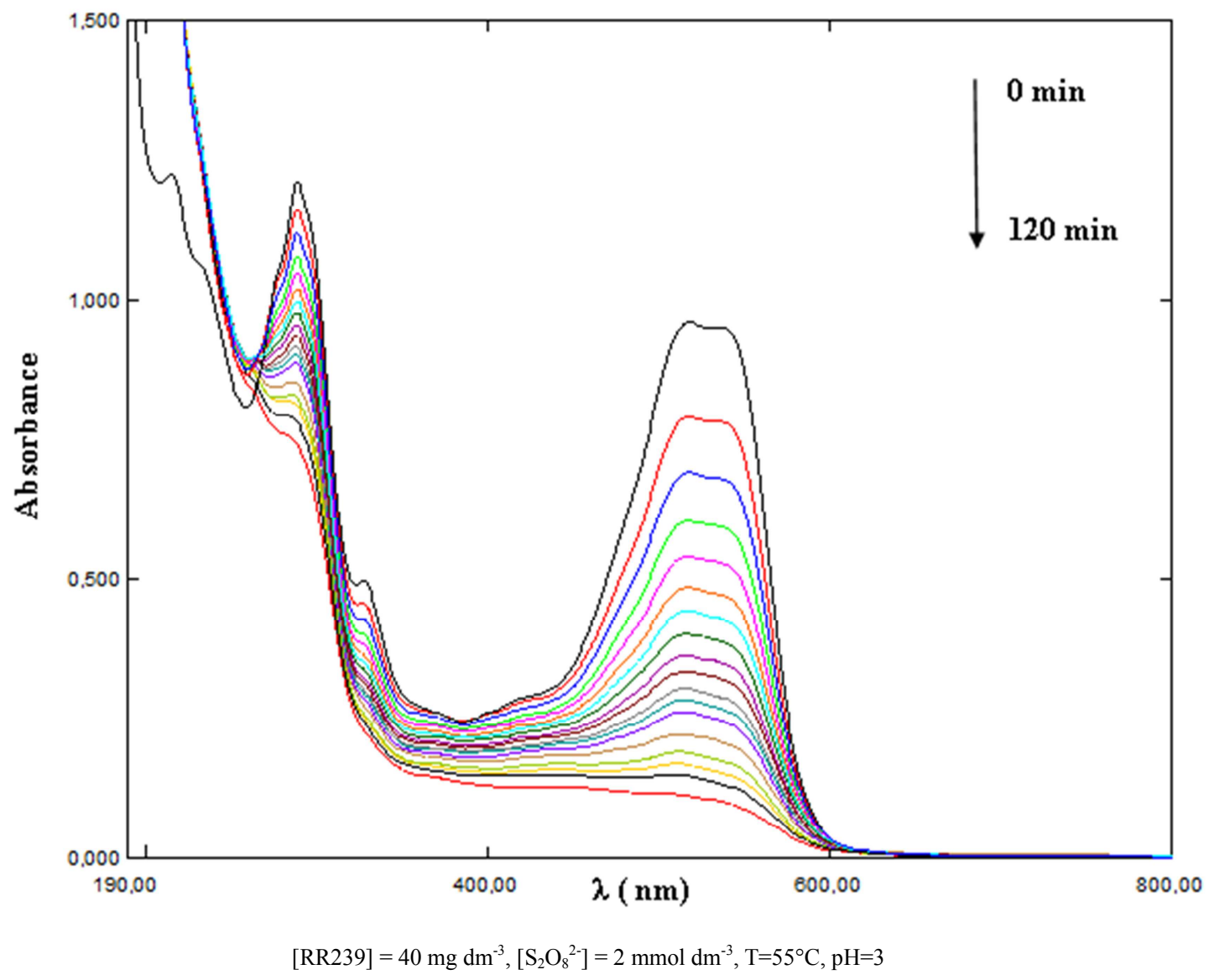

Figure 6. UV-visible spectra of RR239.

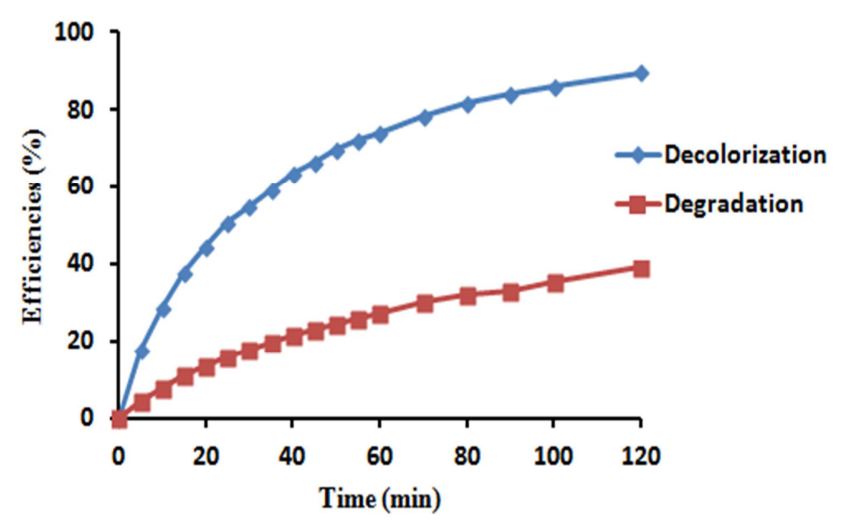

[RR239] $=40 \mathrm{mg} \mathrm{dm}^{-3},\left[\mathrm{~S}_{2} \mathrm{O}_{8}{ }^{2-}\right]=2 \mathrm{mmol} \mathrm{dm}^{-3}, \mathrm{~T}=55^{\circ} \mathrm{C}, \mathrm{pH}=3$

Figure 7. Decolorization and degradation efficiencies of RR239.

\section{Conclusion}

In the present study, decolorization of RR239 azo dye via heat activated persulfate was investigated. A series of experiments was carried out to evaluate the effect of temperature, $\mathrm{pH}$ and $\mathrm{S}_{2} \mathrm{O}_{8}{ }^{2-}$ concentration. Decolorization efficiency increased with increasing temperature up to $55^{\circ} \mathrm{C}$ and further increase in temperature did not enhance decolorization. Activation energy was calculated as $108.75 \mathrm{~kJ}$ $\mathrm{mol}^{-1}$ using Arrhenius equation. 89.67\% of decolorization was observed at $\mathrm{pH}=3$, whereas $54.04 \%$ and $49.58 \%$ decolorization efficiency values were obtained at $\mathrm{pH}=7$ and $\mathrm{pH}=9$, respectively. When $\left[\mathrm{S}_{2} \mathrm{O}_{8}{ }^{2-}\right]_{\mathrm{o}} /[\mathrm{RR} 239]_{\mathrm{o}}$ mole ratio was increased from 12.83 to 102.64 decolorization efficiency was improved from $\% 36.62$ to $\% 96.58$. Since $\mathrm{SO}_{4}{ }^{-}$firstly attacked to $-\mathrm{N}=\mathrm{N}-$ bond of dye degradation efficiency was lower than decolorization efficiency at the end of 120 minutes, thus requiring longer time for complete degradation. Experimental results confirmed that decolorization of RR239 was achieved effectively via heat activated $\mathrm{S}_{2} \mathrm{O}_{8}{ }^{2-}$. 


\section{References}

[1] L. Biliska, M. Gmurek, and S. Ledakowicz, "Comparison between industrial and simulated textile wastewater treatment by AOPs - Biodegradability, toxicity and cost assessment" Chem. Eng. J., vol. 306, pp. 550-559, 2016.

[2] C. R. Holkar, A. J. Jadhav, D. V. Pinjari, N. M. Mahamuni, and A. B. Pandit, "A critical review on textile wastewater treatments: Possible approaches" J. Environ. Manage., vol.182, pp.351-366, 2016.

[3] H. U. Farouk, A. A. A. Raman and W. M. A. W Daud, " $\mathrm{TiO}_{2}$ catalyst deactivation in textile wastewater treatment: Current challenges and future advances" J. Ind. Eng. Chem., vol. 33, pp. 11-21, 2016.

[4] V. J. P. Vilar, L. X. Pinho, A. M. A. Pintor and R. A. R. Boaventura, "Treatment of textile wastewaters by solar-driven advanced oxidation processes" Sol. Energy, vol. 85, pp. 1927-1934, 2011.

[5] I. K. Konstantinou and T. A. A lbanis, " $\mathrm{TiO}_{2}$-assisted photocatalytic degradation of azo dyes in aqueous solution: kinetic and mechanistic investigations A review" Appl. Catal. Environ., Vol. 49, pp. 1-14, 2004.

[6] D. Salari, A. Niaeri, S. Aber and M. H. Rasoulifard, "The Photooxidative destruction of C. I. Basic Yellow 2 using $\mathrm{UV} / \mathrm{S}_{2} \mathrm{O}_{8}{ }^{2-}$ process in a rectangular continuous photoreactor" J. Hazard. Mater., vol. 166, pp. 61-66, 2009.

[7] K.-C. Huang, R. A. Couttenye and G. E. Hoang, "Kinetics of heat-assisted persulfate oxidation of methyl tert-butyl ether (MTBE)" Chemosphere, vol. 49, pp. 413-420, 2002.

[8] G.-D. Fang, D. D. Dionysiou, D.-M. Zhou, Y., Wang, X.- D. Zhu, J.- X. Fan, L. Cang and Y.- J. Wang. "Transformation of polychlorinated biphenyls by persulfate at ambient temperature" Chemosphere, vol. 90, pp. 1573-1580, 2013.

[9] L. Zhao, H. Hou, A. Fujii, M. Hosomi and F. Li, "Degradation of 1,4-dioxane in water with heat-and $\mathrm{Fe}^{2+}$-activated persulfate oxidation" Environ. Sci. Pollut. Res., vol. 21, pp. 7457-7465, 2014.

[10] C. Jiang, Y. Ji, Y. Shi, J. Chen and T. Cai, "Sulfate radical-based oxidation of fluoroquinolone antibiotics: Kinetics, mechanisms and effects of natural water matrices" Water Res., vol. 106, pp. 507-517, 2016.

[11] M. C. Yeber, L. Diaz and J. Fernandez, "Catalytic activity of the $\mathrm{SO}_{4}{ }^{--}$radical for photodegradation of the azo dye Cibacron
Brilliant Yellow 3 and 3,4-dichlorophenol: Optimization by application of response surface methodology" J. Photochem. Photobiol. A: Chem., vol. 215, pp. 90-95, 2010.

[12] S. Yang., P. Wang, X. Yang, L. Shan, W. Zhang, X. Shao and R. Niu, "Degradation efficiencies of azo dye Acid Orange 7 by the interaction of heat, UV and anions with common oxidants: Persulfate, peroxymonosulfate and hydrogen peroxide" J. Hazard. Mater., vol. 179, pp. 552-558, 2010.

[13] A. R. Khataee, "Optimization of UV-promoted peroxydisulfate oxidation of C. I. Basic Blue 3 using resonse surface methodology" Environ. Technol., vol. 31, pp. 73-86, 2010.

[14] J. Saien, A. R. Soleymani and J. H. Sun, "Parametric optimization of individual and hybridized AOPs of $\mathrm{Fe}^{2+} / \mathrm{H}_{2} \mathrm{O}_{2}$ and $\mathrm{UV} / \mathrm{S}_{2} \mathrm{O}_{8}{ }^{2-}$ for rapid dye destruction in aqueous media" Desalination, vol. 279, pp. 298-305, 2011.

[15] C. Tan, N. Gao, Y. Deng, N. An and J. Deng, "Heat-activated persulfate oxidation of diuron in water" Chem. Eng. J., vol. 203 , pp. 294-300, 2012.

[16] A. Ghauch, A. M. Tuqan and N. Kibbi, "Ibuprofen removal by heated persulfate in aqueous solutions: A kinetics study" Chem. Eng. J., vol. 197, pp. 483-492, 2012.

[17] A. Ghauch, A. M. Tuqan, N. Kibbi and S. Geryes, "Methylene blue discoloration by heated persulfate in aqueous solution" Chem. Eng. J., vol. 213, pp. 259-271, 2012.

[18] R. Li, J. Kong, H. Liu, P. Chen, G. Liu, F. Li and W. Lv, “A sulfate radical based ferrous-peroxydisulfate oxidative system for indomethacin degradation in aqueous solutions" RSC Adv., vol. 7, pp. 22802-22809, 2017.

[19] A. Ghauch and A. M. Tuqan, "Oxidation of bisoprolol in heated persulfate $/ \mathrm{H}_{2} \mathrm{O}$ systems: Kinetics and products" Chem. Eng. J., vol. 183, pp. 162-171, 2012.

[20] L. Ismail, C. Ferronato, L. Fine, F. Jaber and J. M. Chovelona, "Elimination of sulfaclozine from water with $\mathrm{SO}_{4}{ }^{-}$radicals: Evaluation of different persulfate activation methods" Appl. Catal. B, vol. 201, pp. 573-581, 2017.

[21] P. Hu and M. Long, "Cobalt-catalyzed sulfate radical-based advanced oxidation: A review on heterogeneous catalysts and applications" App. Catal. B, vol. 181, pp. 103-117, 2016.

[22] S. Nasseri, A. H. Mahvi, M. Seyedsalehi, K. Yaghmaeian, R. Nabizadeh, M. Alimohammadi and G. H. Safari, "Degradation kinetics of tetracycline in aqueous solutions using peroxydisulfate activated by ultrasound irradiation: Effect of radical scavenger and water matrix" J. Mol. Liq., vol. 241, pp.704- 714, 2017. 